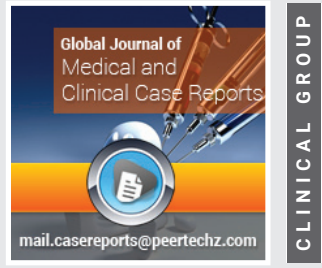

\title{
Apraxia: Definition, clinical contexts, neurobiological profiles and clinical treatments
}

Received: 27 June, 2020

Accepted: 02 July, 2020

Published: 03 July, 2020

*Corresponding author: Giulio Perrotta, Department of Criminal and Investigative Psychology Studies, University of Federiciana, Cosenza, Italy, Tel: +393492108872; E-mail: giuliosr1984@hotmail.it

https://www.peertechz.com

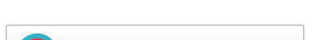
(D) Check for updates

\begin{abstract}
Starting from the general concept of Apraxia, the present work focuses on the clinical, neurobiological, and functional aspects of the morbid condition, suggesting a multidimensional treatment between rehabilitation exercises for lost skills and psychotherapy.
\end{abstract}

\section{Contents of the manuscript}

Apraxia (from the Greek a-praxía, inability to do) is a neuropsychological disturbance of the voluntary movement, defined as the inability to perform coordinated gestures directed towards a certain goal, although the will of the subject and his ability are maintained unaltered physical education; as in many other neurological diseases, people with this disorder generally don't know they are. To exclude that it is hyposthenia, however, as a differential diagnosis, we observe the various muscles engaged as a whole, for the chosen action, as well as a family history to better define the exact diagnosis (as certain forms can be also family members). Computed tomography and magnetic resonance imaging can ultimately prove useful in that they precisely define the nature of the injury-causing the disorder [1-4].

Following the brain injury, the deficits are not always obvious or it happens that certain spontaneous recoveries are not completely complete, manifesting themselves in apraxic phenomena of various levels (mild, moderate, serious, very serious). For a correct evaluation it is therefore important to exclude in the differential diagnosis all cognitive and not cognitive deficits that could compromise the patient's psychic and/or sensory abilities, as happens in dementia, personality disorders, blindness, and deafness, carefully evaluating all types of gestures $[5,6]$.

a) transitive gestures: it is the concrete manipulation of objects in an activity that can be simple (use a comb, a toothbrush, a match or a pin) or complex/articulated (light a candle with a matchbox or pack a package);

b) intransitive gestures: these are gestures that do not involve the use of objects (on order and imitation) but are equally physical, symbolic (a sign of the cross, military salute or say goodbye, mimicry (ironing, planting a nail, washing teeth) or arbitrary imitative (fingers crossed to form an 8);

c) arbitrary sequences (beat the hand punch, palm, cut, punch, palm, cut);

d) contrasting gestures (strong hit - weak hit);

e) graphic and construction activities (spontaneous or dictated writing and drawing, reproduction of geometric figures with the use of toothpicks or using special games and reproduction of graphic sequences such as line, point, curve, line, point, curve);

f) common daily activities concerning clothing (wearing a jacket and trousers or making a tie).

According to the level of elaboration of the motor act, the following apraxic forms are therefore distinguished [4.7-9]:

ideational apraxia, in which the dysfunction is in the process of mental representation of the gesture or sequence of movements to be performed. It appears to be caused by a lesion of the temporal-parietal-occipital crossroads of the 
left hemisphere. In the use tests of objects, frequent errors of omission, erroneous use, incorrect localization, clumsiness, perplexity and sequence errors are observed;

ideomotor apraxia, in which dysfunction occurs in the process of translating the gesture with meaning into the motor program for the individual muscle groups. The lesion usually concerns the left cerebral hemisphere, in particular, a lesion of the parietal lobe causes more frequently the severe form, compared to a frontal lesion of the lateral premotor area. An injury to the corpus callosum can cause this apraxic form in the ipsilateral limbs to the dominant hemisphere. The difficulties in the imitation tests highlight the ideomotor form since the idea of the gesture is provided by the experimenter, therefore there is no ideational one;

acrokinetic apraxia involves lesions in the premotor areas, with preserved ideation but lack of fluidity, slowness and awkwardness, difficulty of passing synchronously, and organized from the contraction of a muscle to the subsequent relaxation. In this type of apraxia, both spontaneous and voluntary movements are affected, some difficulties increase according to the complexity of the task, but do not vary based on the type of object or imitation.

constructive apraxia is characterized by the inability, following a brain injury, to correctly produce threedimensional constructions or two-dimensional drawings, both from memory and imitation. It can result in both left and right brain injuries. Usually, when the lesion affects the left side of the brain, the subject tends to simplify the drawing and make it smaller; when there are right lesions, severe spatial disorganization and loss of detail on the left side are observed in the drawing. Constructive apraxia may depend on deficits in the visual-spatial analysis systems (right parietal lobe), action planning and monitoring (frontal lobes), tactile and proprioceptive sensitivity, semantic memory;

motor apraxia involves in the disorganization of movement similar to elementary motor disorders, characterized by a reduction in motor spontaneity and by forms of prehension (frontal lesion) and avoidance (parietal lesion) observed in the contralateral embody to the lesion;

dynamic apraxia is characterized by the presence of persevering inability to subject the action to a motor project, for a lesion of the frontal lobe. Limb apraxia is the most studied form as it has a greater impact on quality of life, while oral (or Bucco-facial) apraxia is generally associated with a lesion of the front and central operculum and the anterior portion of the insula.

Brain injury studies currently use techniques such as computed tomography, functional magnetic resonance imaging, single photon emission tomography and positron emission tomography. The renowned neuropsychologist Alexander Romanovich Luria [10], has been conducting cognition studies without the use of imaging technologies for many years, in a large number of patients with brain lesions, and has explored the complex behavior and specific brain functions involving lobes and sub-areas. For example, he has conducted several specific studies on memory and mental organisation, including cases of apraxia, and has found that this lobe is also involved in lesions [11].

The prognosis [12], will depend on the type, size and position of the lesions, the degree of compromise, the age of the patient and the targeted efficacy of pharmacological [13] and rehabilitative therapy and speech therapy and psychotherapy [14], for any comorbidity with the psychological and psychiatric symptoms $[15,16]$, such as anxiety disorders [17], post-traumatic stress disorder [18], depression [19], obsessions [20], suicidal risk [21], personality disorders and as a consequence of degenerative neurological diseases [22-25].

\section{References}

1. Foundas AL (2013) Apraxia: neural mechanisms and functional recovery. Handb Clin Neurol 110: 335-345. Link: https://bit.ly/3eOuDUi

2. Kandel ER, Schwartz J, Jessel T, Siegelbaum SA, Hudspeth AJ (2014) Principi di Neuroscienze. Casa Editrice Ambrosiana, quarta ed. Link: https://bit.ly/2As8IDA

3. Làdavas E, Berti A (2002) Neuropsicologia, Bologna, il Mulino.

4. Goldenberg G (2003) Apraxia and Beyond: life and work of Hugo Liepmann Cortex 39: 509-524. Link: https://bit.ly/31BQhHJ

5. Perrotta G (2019) Psicologia generale, Luxco Ed., $11^{\text {th }}$ ed.

6. Perrotta G (2019) Psicologia clinica, Luxco Ed., 1st ed

7. Cubelli R, Della Sala G (2018) Constructional apraxia. Cortex 104: 127. Link: https://bit.ly/2ZtBc8u

8. Etcharry-Bouyx F, Gall D, Jarry C, Osiurak F (2017) Gestural apraxia. Rev Neurol 173: 430-439. Link: https://bit.ly/3dZwBjG

9. Pearce JMS (2009) Hugo Karl Liepmann and Apraxia. Clin Med (Lond). 9: 466 470. Link: https://bit.ly/2YS9vqH

10. Aversi-Ferreira TA, Tamaishi-Watanabe $\mathrm{BH}$, de Fátima Magri MP, AversiFerreira RAGMF (2019) Neuropsychology of the temporal lobe: Luria's and contemporary conceptions. Dement Neuropsychol 13: 251-258. Link: https://bit.ly/3ikeqZc

11. Walusinski O, Boller F, Henderson V (2019) Shining a light on some of the most famous 19th and 20th century's neuropsychologist. Front Neurol Neurosci 44: 192-229. Link: https://bit.ly/3gkMRNs

12. Basilakos A (2018) Contemporary approaches to the management of post-stroke apraxia of speech. Semin Speech Lang 39: 25-36. Link: https://bit.ly/2NQB11m

13. Saito M, Matsui Y, Otani Y, Miyaoka H (2005) Liepmann's phenomenon during benzodiazepine withdrawal. Am J Psychiatry 162: 811. Link: https://bit.ly/2AoLqOX

14. Perrotta G (2020) The strategic clinical model in psychotherapy: theoretical and practical profiles. J Addict Adolescent Behav 3: 5. Link: https://bit.ly/2YQzMWk

15. Perrotta G (2019) The reality plan and the subjective construction of one's perception: the strategic theoretical model among sensations, perceptions, defence mechanisms, needs, personal constructs, beliefs system, social influences and systematic errors. Journal of Clinical Research and Reports. J Clinical Research and Reports 1: 9

16. Perrotta G (2020) Psychological trauma: definition, clinical contexts, neural correlations and therapeutic approaches. Current Research in Psychiatry and Brain Disorders. Curr Res Psychiatry Brain Disord: CRPBD-100006. 
17. Perrotta G (2019) Anxiety disorders: definitions, contexts, neural correlates and strategic therapy, Journal of Neurology and Neuroscience. J Neur Neurosci 6: 046. Link: https://bit.ly/2AmsP5V

18. Perrotta G (2019) Post-traumatic stress disorder: Definition, contexts, neural correlations and cognitive-behavioral therapy. J Pub Health Catalog 2: 40-47.

19. Perrotta G (2019) Depressive disorders: Definitions, contexts, differential diagnosis, neural correlates and clinical strategies. Peertechz Arch Depress Anxiety 5: 009-033. Link: https://bit.ly/2YSdW4Q

20. Perrotta G (2019) Obsessive-Compulsive Disorder: definition, contexts, neural correlates and clinical strategies. Cientific Journal of Neurology 1: 08-16. Link: https://bit.ly/2CWgYfO

21. Perrotta G (2020) Suicidal risk: definition, contexts, differential diagnosis, neural correlates and clinical strategies. J Neuroscience Neurological Surgery 6: 4. Link: https://bit.ly/31P8thh
22. Perrotta G (2019) Alzheimer's disease: definition, contexts, neural correlates, strategies and clinical approaches. Journal of Aging Studies and Therapies. J Aging Stud Ther 1: 8. Link: https://bit.ly/3glp2W0

23. Perrotta G (2019) Parkinson's disorder: definition, contexts, neural correlates, strategies and clinical approaches. J Neurosci Neurol Surg 4. Link: https://bit.ly/2VGEHai

24. Perrotta G (2020) General overview of "human dementia diseases": definitions, classifications, neurobiological profiles and clinical treatments. Gerontol Geriatric Stud 6: GGS.000626. Link: https://bit.ly/2NRfbuR

25. Segen JC (2006) Concise Dictionary of Modern Medicine, New York, McGrawHill.

\section{Discover a bigger Impact and Visibility of your article publication with}

\section{Peertechz Publications}

\section{Highlights}

* Signatory publisher of ORCID

* Signatory Publisher of DORA (San Francisco Declaration on Research Assessment)

* Articles archived in worlds' renowned service providers such as Portico, CNKI, AGRIS, TDNet, Base (Bielefeld University Library), CrossRef, Scilit, J-Gate etc.

* Journals indexed in ICMJE, SHERPA/ROMEO, Google Scholar etc.

* OAI-PMH (Open Archives Initiative Protocol for Metadata Harvesting)

* Dedicated Editorial Board for every journa

* Accurate and rapid peer-review process

* Increased citations of published articles through promotions

* Reduced timeline for article publication

Submit your articles and experience a new surge in publication services (https://www.peertechz.com/submission).

Peertechz journals wishes everlasting success in your every endeavours.

Copyright: () 2020 Perrotta G. This is an open-access article distributed under the terms of the Creative Commons Attribution License, which permits unrestricted use, distribution, and reproduction in any medium, provided the original author and source are credited. 